\title{
Development of a prenatal smoking cessation counseling scale for public health nurses in Japan
}

\author{
Meng Li', Reiko Okamoto', Misaki Kiya ${ }^{1}$, Miho Tanaka ${ }^{1}$, Keiko Koide ${ }^{1}$
}

\begin{abstract}
INTRODUCTION This study aimed to develop a scale to measure prenatal smoking cessation counseling for Japanese public health nurses (PHNs).

METHODS A cross-sectional study was conducted via an anonymous, self-administered questionnaire. The sample included 1933 PHNs working in 424 municipal health centers nationwide, which were randomly selected. We created the draft scale based on semi-structured interviews, previous studies, and preliminary survey. Additionally, we conducted back translation for English version of the draft scale to be applicable in English countries. The analytic strategy consisted of item analysis, exploratory factor analysis, and differentiation by 'known groups' .

RESULTS A total of 550 responses $(28.5 \%)$ were included in the analysis. Most of the respondents were female $(98.2 \%)$ and the mean age was $37.5 \pm 9.37$ years. In the exploratory factor analysis, two factors were extracted and the factor loadings for all items were greater than 0.40 . The first factor with eleven items was named as 'basic counseling' and the second factor with seven items was named as 'advanced counseling'. The Cronbach's alpha of the scale was 0.918, and the cumulative contribution was $44.908 \%$. Multiple comparisons by experience years working as a PHN revealed significant differences in the scale and two factors.

CONCLUSIONS In this study, we initially developed the prenatal smoking cessation counseling scale for Japanese PHNs, and the reliability and validity of the scale were considered to be acceptable.
\end{abstract}

\author{
AFFILIATION \\ 1 Division of Health Sciences, \\ Osaka University Graduate \\ School of Medicine, Osaka, \\ Japan \\ CORRESPONDENCE TO \\ Reiko Okamoto. Division \\ of Health Sciences, Osaka \\ University Graduate School \\ of Medicine, 1-7 Yamadaoka, \\ Suita City, Osaka Prefecture \\ 565-0871, Japan. \\ E-mail: reiko@sahs.med. \\ osaka-u.ac.jp
}

KEYWORDS pregnant women, smoking cessation, counseling, public health nurses, Japan

Received: 29 April 2021 Revised: 20 June 2021 Accepted: 8 July 2021

\section{INTRODUCTION}

Maternal smoking during pregnancy is a modifiable risk factor influencing maternal and fetal health ${ }^{1}$. Maternal smoking and exposure to secondhand smoke (SHS) during pregnancy are associated with increased risks for ectopic pregnancy, preterm premature rupture of the membrane, placenta previa, placental abruption, miscarriage, stillbirth, preterm birth $(<37$ weeks gestation), low birthweight $(<2500 \mathrm{~g})$, small for gestational age, and congenital anomalies such as cleft lip ${ }^{2-10}$. After birth, the risk of sudden infant death syndrome (SIDS) is higher among the offspring of women who smoked during or after pregnancy ${ }^{11}$. According to a recent systematic review, global prevalence of maternal smoking during pregnancy is estimated to be $1.7 \%$. The prevalence of smoking during pregnancy is higher than $10 \%$ in 29 of 174 countries and more than $20 \%$ in 12 countries ${ }^{12}$.

In Japan, the prevalence of maternal smoking during pregnancy is estimated to be between $5.1 \%$ and $7.5 \%{ }^{12}$, and the prevalence of paternal smoking is reported to be $47 \%$ in the first trimester and $46 \%$ in the second and third trimesters ${ }^{13}$. In light of this troubling fact, the Japanese government has enacted several national-level legal regulations and policies, such as 'Health Japan 21' and 'Health Promotion Act' where reducing maternal smoking and SHS exposure during pregnancy were recorded ${ }^{14,15}$. At the prefectural and municipal levels, local governments have implemented a series of measures such as the Kanagawa prefecture 
anti-smoking ordinance according to national regulations and policies ${ }^{16}$. Of these, previous study has reported that approximately $80 \%$ of the professionals who play a central role in prefectural and municipal measures on tobacco control are $\mathrm{PHNs}^{16}$. Furthermore, in municipal level, PHNs working in health centers engage with community members with a wide range of health levels including infants, young children, elderly people, pregnant women, and people with disabilities ${ }^{17}$. Therefore, PHNs play an important role in preventing maternal smoking and SHS exposure during pregnancy in municipalities. Additionally, previous study has reported that PHNs can reduce maternal smoking and SHS exposure during pregnancy because they have many opportunities, such as the issuance of maternal and child health handbook, telephone counseling, classroom sessions, home visits, and health checkups of infants, to engage with pregnant women ${ }^{18}$. Psychological intervention has been recommended as the first line of treatment to help pregnant women to quit smoking ${ }^{19,20}$. The World Health Organization (WHO) has recommended that healthcare providers routinely offer advice and psychological interventions for tobacco cessation to pregnant women who are either current tobacco users or recent tobacco quitters ${ }^{1}$. As a brief psychological intervention method, the 5As model (Ask, Advise, Assess, Assist, and Arrange follow-up $)^{20}$ has been recommended to be used at the first antenatal appointment and subsequent appointments, in previous literature ${ }^{21}$. Japanese guidelines for smoking cessation also recommend healthcare providers to adopt the 5As model for smoking cessation in general practice settings such as outpatient care and medical examination $^{22}$. Additionally, previous literature has reported that pregnancy is an excellent opportunity to quit smoking because patients visit the clinic regularly and smoking cessation may be motivated effectively ${ }^{1,22}$. Overall, psychological interventions should be prioritized to help women to quit smoking, and the 5As model can be applicable for smoking cessation intervention during pregnancy.

In Japan, regarding psychological interventions for smoking cessation, previous studies have mainly centered on nurses' behavioral counseling in Japanese smoking cessation therapy. These studies have reported that nurses' behavioral counseling skills such as providing patients with reasons to quit, helping patients to cope with recovery symptoms, and managing the patient's weight gain, can help smokers to quit smoking by reinforcing patients' selfefficacy and controlling the strength of the patients' craving $^{23-25}$. Additionally, previous study has reported that most nurses felt that although they assessed and documented the tobacco status of cancer patients, they were not successful in providing cessation advice, assessing patient readiness to quit, and providing individualized information on the harmful effects of tobacco use in cancer and general hospitals ${ }^{26}$. Overall, nurses' behavioral counseling has been used for smoking cessation interventions, whereas the levels of counseling skills are different among Japanese nurses.

To date, although PHNs are expected to play an important role in preventing maternal smoking and SHS exposure during pregnancy, there are no scales to measure prenatal smoking cessation counseling among Japanese PHNs. Therefore, this study aimed to develop a scale to measure prenatal smoking cessation counseling for Japanese PHNs. The scale will be expected to improve the behavioral counseling skills by measuring prenatal smoking cessation counseling with this scale.

\section{METHODS}

\section{Design and sample}

We conducted a cross-sectional study from 1 January to 15 February 2020 via an anonymous, selfadministered questionnaire. The sample included 1933 PHNs working in 424 municipal health centers nationwide. The study was approved by the Ethical Committee of Observation Research at Osaka University Hospital (Approval No: 19308, 28 November 2019).

\section{Creating the draft scale}

Creation of the draft scale was divided into five stages. First, we discussed the feasibility of developing the scale using the 5As model among the researchers. Second, we conducted semi-structured interviews with 10 PHNs who had abundant experience in maternal and child health, to obtain their opinions for prenatal smoking cessation counseling. Third, we extracted 68 items from the semi-structured interviews and previous studies ${ }^{1,19,21,22,27-31}$, and subsequently categorized them according to the $5 \mathrm{As}$ model. Fourth, we conducted a preliminary survey 
of $27 \mathrm{PHN}$ to obtain opinions on the contents and wordings, and then completed the draft scale based on the opinions and our considerations. The draft scale included 36 items rated on a 6-point Likert scale ( 0 to 5 representing 'strongly disagree' to 'strongly agree').

After completing the cross-sectional survey, we excluded five items in the analysis of scale development, because these items were already recorded in the pregnancy notification form which meant PHNs have implemented these contents in the usual work.

\section{Back translation for English version of the draft scale}

To be available in English for other countries, we conducted back translation for the English version of the draft scale. The back translation process was divided into five stages. First, we invited two native English translators who were very familiar with Japanese translations to conduct independent forward translation on the draft scale. Second, we compared and discussed the two forward translations and the draft scale among the researchers, and subsequently created an integrated forward translation version. Third, we invited two native Japanese translators who were very familiar with English translations to carry out independent back-translation on the integrated forward translation version. Fourth, we compared and discussed the two back-translated versions and the original scale draft among the researchers and then compiled an integrated back translation version of the scale draft. Finally, we invited seven native English speakers to check the wording, grammar and translation congruence of English on the integrated back translation version to finalize the English version of the scale draft.

\section{Data collection}

First we randomly selected 1933 PHNs from 424 municipal health centers nationwide according to the number of full-time PHNs from Official Statistics of Japan in e-Stat ${ }^{32}$. Second, we searched the addresses of 424 municipal health centers on the internet, and sent an envelope including the request for participant cooperation, the return envelope, and the questionnaire, to 424 municipal health centers. Third, to increase the response rate, we sent a reminder in approximately one month after the questionnaire was mailed out.

\section{Statistical analysis}

The statistical analysis consisted of item analysis, exploratory factor analysis, and differentiation by 'known groups'.

For item analysis, the average and standard deviation of the 31 item responses were firstly computed. In examining response biases, the ceiling and floor effects were assessed by the average value $\pm 1 \mathrm{SD}$ for each item, and the items that exceeded the maximum value or minimum value were excluded. To avoid duplicate items, the Pearson's correlation coefficient with $r \geq 0.75$ was considered to be similar in the semantic contents, and one item was excluded ${ }^{33}$. To verify the discriminative power of each item, we used the quartile method to divide them into the top quartile group (good group) and the low quartile group (poor group). Subsequently, we compared the average values for each item's scores between the two groups. The items that had no significant difference were excluded. Additionally, we performed the inter-item and total-item analysis to determine the correlations between scale items as well as the correlations between each item and the sum score of scale items, and those with correlation coefficient $\mathrm{r}<0.3$ were excluded ${ }^{34}$.

For exploratory factor analysis, we performed the principal component method with promax rotation. The items with factor loadings $\geq 0.40$ in one of the extracted factors were collected together to construct the common factor ${ }^{34}$. The items that did not meet the criteria were excluded, and the analysis was repeated. Finally, the extracted factor was named to reflect the included items best. For reliability, Cronbach's alpha coefficients were used to verify internal consistency reliability. For differentiation by 'known groups', we performed one-way analysis of variance (ANOVA) for the relationship between years of experience as a PHN and the factors ${ }^{34}$.

Data analysis was performed using SPSS Statistics 25.0 for Microsoft Windows (IBM Japan, Tokyo, Japan). For all analyses, $\mathrm{p}<0.05$ was considered statistically significant.

\section{RESULTS}

Of the questionnaires mailed to PHNs, 599 (31.0\%) responses were received of which 49 were excluded because they missed an answer or had multiple answers for the questions. Finally, 550 responses 
Table 1. Characteristics of respondents included in the analysis $(\mathrm{N}=550)$

\begin{tabular}{|c|c|c|c|c|}
\hline Characteristics & $n$ & $\%$ & Mean & SD \\
\hline \multicolumn{5}{|l|}{ Gender } \\
\hline Female & 540 & 98.2 & & \\
\hline Male & 10 & 1.8 & & \\
\hline Age (years) & & & 37.5 & 9.37 \\
\hline$\leq 29$ & 141 & 25.6 & & \\
\hline $30-39$ & 170 & 30.9 & & \\
\hline $40-49$ & 173 & 31.5 & & \\
\hline$\geq 50$ & 66 & 12.0 & & \\
\hline $\begin{array}{l}\text { Experience as a public } \\
\text { health nurse (years) }\end{array}$ & & & 12.5 & 9.47 \\
\hline$\leq 5$ & 185 & 33.6 & & \\
\hline $6-15$ & 159 & 28.9 & & \\
\hline$\geq 16$ & 206 & 37.5 & & \\
\hline \multicolumn{5}{|l|}{ Work position } \\
\hline Staff & 324 & 58.9 & & \\
\hline Assistant managerial level & 190 & 34.5 & & \\
\hline Managerial level & 36 & 6.5 & & \\
\hline \multicolumn{5}{|l|}{ Educational level } \\
\hline Vocational college & 153 & 27.8 & & \\
\hline Junior college & 86 & 15.6 & & \\
\hline University (4 years) & 305 & 55.5 & & \\
\hline Master's program & 6 & 1.1 & & \\
\hline
\end{tabular}

(28.5\%) were included in the analysis.

Characteristics of the respondents are summarized in Table 1. Most of the respondents were female $(98.2 \%)$ and the mean age was $37.5 \pm 9.37$ years. The average years working as a PHN was $12.5 \pm 9.47$. More than half ( $58.9 \%)$ were staff level, followed by assistant managerial level (34.5\%). More than half (55.5\%) had a 4-year university education, followed by those who had completed vocational college $(27.8 \%)$ and junior college (15.6\%).

The results of the item analysis are summarized in the Supplementary file. Six items (items 1, 2, 14, 17,18 and 20) showed the ceiling effect and item 12 showed the floor effect. Thus, these items were excluded. Nine pairs (items 5-6, 25-26, 27-28, 28$29,29-30,30-31,27-29,27-30$ and 28-30) were considered to be similar in the semantic contents with the correlation coefficient $\geq 0.75$. Thus, five items (item 5, 25, 28, 29, and 30) were excluded. The mean value of each item between the first and fourth quartile groups had a statistically significant difference $(p<0.001)$. Moreover, the correlation coefficient between scale items ranged 0.497-0.712 and the correlation coefficient between each item and the total scale ranged $0.556-0.752$.

Exploratory factor analysis was conducted on the remaining 19 items. Two factors were extracted based on the screen plot criteria, and one item (item 13) was excluded because of low factor loading $(<0.40)$. The factor loadings for all items were greater than 0.40 . The first factor with eleven items was denoted 'basic counseling' because the items included basic counseling skills such as explaining the harmful effects of smoking and SHS, and encouraging the expectant mother to quit smoking using anti-smoking materials like pamphlets, charts, and photos. Similarly, the second factor with seven items was denoted 'advanced counseling' because the items included advanced counseling skills such as providing the methods of quitting smoking and dealing with withdrawal symptoms. Regarding contributing factors, $39.497 \%$ of the variance was explained by the first factor, the second factor explained 5.411\%, and the cumulative contribution was $44.908 \%$. The Cronbach's alpha coefficient of the scale was 0.918 . In the factors, the Cronbach's alpha coefficient of the first factor was 0.864 and for the second factor it was 0.891 . The correlation between the two factors was 0.711 (Table 2).

Regarding the differentiation by 'known groups', multiple comparisons by experience years working as

Table 2. Exploratory factor analysis of the prenatal smoking cessation counseling scale $(\mathrm{N}=550)$

\begin{tabular}{l|l|l|l} 
Item & Factor 1: Basic counseling & Factor & Factor \\
\hline 15 & $\begin{array}{l}\text { If the expectant mother lives with a smoker, I explain the benefits of household members abstaining from } \\
\text { smoking and get the expectant mother to encourage them to quit smoking. }\end{array}$ & 0.719 & -0.062 \\
16 & $\begin{array}{l}\text { If the expectant mother lives with a smoker, I explain methods by which the expectant mother can avoid } \\
\text { secondhand smoke. }\end{array}$ & 0.698 & -0.050
\end{tabular}


Table 2. Continued

\begin{tabular}{|c|c|c|c|}
\hline Item & Factor 1: Basic counseling & $\begin{array}{c}\text { Factor } \\
1\end{array}$ & $\begin{array}{l}\text { Factor } \\
2\end{array}$ \\
\hline 10 & I confirm the expectant mother's intention to quit smoking in each interview. & 0.643 & -0.079 \\
\hline 7 & $\begin{array}{l}\text { I use interview techniques such as active listening, acceptance, empathy, and motivational interviewing to } \\
\text { encourage the expectant mother to quit smoking. }\end{array}$ & 0.640 & 0.027 \\
\hline 8 & $\begin{array}{l}\text { I encourage the expectant mother to quit smoking based on her personal traits (personality, medical history, } \\
\text { reasons for smoking, etc.). }\end{array}$ & 0.613 & 0.020 \\
\hline 19 & $\begin{array}{l}\text { If the expectant mother lives with a former smoker who has quit smoking, I compliment household members } \\
\text { on quitting smoking and get the expectant mother to ask them to keep it up. }\end{array}$ & 0.584 & 0.063 \\
\hline 3 & $\begin{array}{l}\text { I explain the harmful effects of the toxic substances contained in tobacco (nicotine, tar, carbon monoxide, } \\
\text { etc.). }\end{array}$ & 0.546 & 0.029 \\
\hline 27 & I confirm the smoking abstinence status of the expectant mother and her household members. & 0.539 & 0.054 \\
\hline 11 & I confirm the expectant mother's stages of behavioral change toward quitting smoking in each interview. & 0.539 & 0.160 \\
\hline 9 & $\begin{array}{l}\text { I use anti-smoking materials like pamphlets, charts, and photos to encourage the expectant mother to quit } \\
\text { smoking. }\end{array}$ & 0.463 & 0.094 \\
\hline 4 & I explain the expectant mother's new role and responsibilities as a mother. & 0.447 & 0.158 \\
\hline Item & Factor 2: Advanced counseling & & \\
\hline 22 & $\begin{array}{l}\text { I provide information on smoking cessation outpatient services and smoking cessation clinics that are covered } \\
\text { by medical insurance. }\end{array}$ & -0.129 & 0.930 \\
\hline 21 & I explain that smoking cessation treatment is 'reliable' and 'not very expensive'. & -0.043 & 0.880 \\
\hline 6 & I explain that smoking cessation treatment increases the success rate of quitting smoking. & & \\
\hline 23 & I recommend the use of online easy-to-use smoking cessation support services and programs. & -.086 & .666 \\
\hline 26 & $\begin{array}{l}\text { I provide some methods on how to deal with withdrawal symptoms after quitting smoking (irritability, } \\
\text { headaches, sleeplessness, etc.). }\end{array}$ & -0.094 & 0.663 \\
\hline 24 & $\begin{array}{l}\text { I recommend the expectant mother to ask for support from her family, friends, co-workers, and other } \\
\text { acquaintances. }\end{array}$ & 0.189 & 0.608 \\
\hline 31 & $\begin{array}{l}\text { If the expectant mother is still smoking, I communicate that she can start smoking cessation treatment at any } \\
\text { time. }\end{array}$ & 0.201 & 0.523 \\
\hline \multicolumn{2}{|c|}{ Cronbach's alpha: 0.918 (for the scale) } & 0.864 & 0.891 \\
\hline \multicolumn{2}{|c|}{ Cumulative proportion $(\%)$} & 39.497 & 44.908 \\
\hline \multicolumn{3}{|c|}{ Factor correlations F1 } & $0.711^{* *}$ \\
\hline
\end{tabular}

Principal component method with promax rotation. ${ }^{* *} p<0.01$. Full list of items given in Supplementary file.

Table 3. Multiple comparisons by experience years working as a PHN ( $\mathrm{N}=550)$

\begin{tabular}{|c|c|c|c|c|c|c|c|}
\hline & \multicolumn{2}{|c|}{ The scale } & \multicolumn{2}{|c|}{ Basic counseling } & \multicolumn{3}{|c|}{ Advanced counseling } \\
\hline & Mean \pm SD & $p$ & Mean \pm SD & $p$ & Mean \pm SD & $p$ & \\
\hline \multicolumn{8}{|c|}{ Experience years working as a PHN } \\
\hline$\leq 5$ & $50.30 \pm 16.11$ & \multirow{3}{*}{]$\left.^{* *}\right]^{* * *}$} & $35.69 \pm 9.96$ & \multirow[t]{3}{*}{]$^{*}$} & $14.61 \pm 7.70$ & \multirow{3}{*}{\multicolumn{2}{|c|}{]$\left._{j *}^{*}\right]^{* * *}$}} \\
\hline $6-15$ & $52.57 \pm 15.41$ & & $35.88 \pm 9.24$ & & $16.69 \pm 7.43$ & & \\
\hline$\geq 16$ & $57.56 \pm 15.76$ & & $38.24 \pm 9.24$ & & $19.33 \pm 7.75$ & & \\
\hline
\end{tabular}

${ }^{*} \mathrm{p}<0.05,{ }^{* *} \mathrm{p}<0.01,{ }^{* * *} \mathrm{p}<0.001$

a PHN revealed significant differences between 6-15 years and $\geq 16$ years, and $\leq 5$ years and $\geq 16$ years in the scale and basic counseling, and $\leq 5$ years and $6-15$ years, $6-15$ years and $\geq 16$ years, and $\leq 5$ years and $\geq 16$ years in advanced counseling (Table 3).

\section{DISCUSSION}

The 5As model has been frequently used for smoking 
cessation interventions in previous studies ${ }^{35-42}$. However, there are no scales to measure prenatal smoking cessation counseling. Therefore, the scale presented here is the first instrument to measure the prenatal smoking cessation counseling among Japanese PHNs. Regarding the reliability of the scale, Boateng et al. ${ }^{34}$ reported that an alpha coefficient of 0.70 has often been regarded as an acceptable threshold for reliability. However, 0.80 and 0.95 are preferred for the psychometric quality of scales. In this study, the Cronbach's alpha coefficient of the scale was 0.918 , and the two factors were both greater than 0.85 . Therefore, the scale and two factors were considered to be preferred for the psychometric quality of scales.

The scale was structured with 18 items covering two factors: basic counseling and advanced counseling. The basic counseling encompassed some basic skills such as explaining the harmful effects of smoking and SHS, and encouraging the expectant mother to quit smoking using anti-smoking materials like pamphlets, charts, and photos. The advanced counseling encompassed some advanced skills such as providing the methods of quitting smoking and dealing with withdrawal symptoms. The contents were extracted from the qualitative study and previous studies ${ }^{1,19,21,22,27-31}$, and assessed by $27 \mathrm{PHNs}$ who had extensive experience in maternal and child health. Therefore, the content validity was considered to be preferred. For construct validity, the factor loadings for all items were greater than 0.40 , which met the criteria in the exploratory factor analysis ${ }^{34}$.

This scale was developed to measure prenatal smoking cessation counseling, and to promote nursing interventions for smoking cessation. However, previous studies reported that numerous factors were associated with nursing interventions for smoking cessation. For example, a recent narrative review grouped these factors into four conceptually similar categories including socioeconomic factors, smoking-related factors, motivational factors, and enabling factors and barriers ${ }^{43}$. Additionally, a previous qualitative study in Belgium reported that barriers affecting midwives and gynecologists providing smoking cessation during pregnancy were fear of provoking resistance and lack of time and communication skills regarding smoking cessation ${ }^{44}$. Overall, nursing interventions for prenatal smoking cessation will need to be improved based on the identified factors in future work.

There are three suggestions for scale utilization. First, the scale may be used to evaluate the effects of smoking cessation intervention training. In Japan, there are several smoking cessation intervention training programs such as Japan Smoking Cessation Training Outreach Project (J-STOP). However, there are no scales to evaluate prenatal smoking cessation counseling. Second, the contents of the scale draft may be used in primary PHN education. The contents are extracted from the qualitative study and previous literature such as Japanese guidelines for smoking cessation. Third, the perceptions and attitudes of PHNs for their supportive role in promoting prenatal smoking cessation may be improved by developing the scale.

\section{Strengths and limitations}

This study has several limitations. First, the effective response rate in this study was only $28.5 \%$. Thus, the sample may not be representative of PHNs nationwide. Second, the scale was developed to measure prenatal smoking cessation counseling for Japanese PHNs. However, to be available in other countries in English, we conducted back translation for the English version of the draft scale. Third, we did not make the testretest study to ensure the reliability of the scale. Thus, the reliability of the scale will need to be evaluate in further work.

\section{CONCLUSIONS}

A nationwide cross-sectional study was conducted via an anonymous, self-administered questionnaire. The sample included 1933 public health nurses working in 424 municipal health centers nationwide. A total of 550 responses $(28.5 \%)$ were included in the analysis. Two factors were extracted, and the factor loadings for all items were greater than 0.40 . The first factor with eleven items was denoted 'basic counseling', and the second factor with seven items was denoted 'advanced counseling'. Cronbach's alpha coefficient of the scale was 0.918 . Multiple comparisons by experience years working as a public health nurse revealed significant differences in the scale and two factors. Therefore, the reliability and validity of the scale were considered to be acceptable. The scale will be expected to measure prenatal smoking cessation counseling and promote nursing interventions for smoking cessation. 


\section{REFERENCES}

1. World Health Organization. WHO recommendations for the prevention and management of tobacco use and second-hand smoke exposure in pregnancy. World Health Organization; 2013. Accessed March 26, 2020. https://apps.who.int/iris/bitstream/ handle/10665/94555/9789241506076_eng.pdf;jsessioni

2. Marufu TC, Ahankari A, Coleman T, Lewis S. Maternal smoking and the risk of still birth: systematic review and meta-analysis. BMC Public Health. 2015;15:239. doi:10.1186/s12889-015-1552-5

3. Pereira PP, Da Mata FA, Figueiredo AC, de Andrade KR, Pereira MG. Maternal Active Smoking During Pregnancy and Low Birth Weight in the Americas: A Systematic Review and Meta-analysis. Nicotine Tob Res. 2017;19(5):497-505. doi:10.1093/ntr/ntw228

4. Pineles BL, Park E, Samet JM. Systematic review and meta-analysis of miscarriage and maternal exposure to tobacco smoke during pregnancy. Am J Epidemiol. 2014;179(7):807-823. doi:10.1093/aje/kwt334

5. Quelhas D, Kompala C, Wittenbrink B, et al. The association between active tobacco use during pregnancy and growth outcomes of children under five years of age: a systematic review and meta-analysis. BMC Public Health. 2018;18(1):1372. doi:10.1186/s12889-018-6137-7

6. Shobeiri F, Masoumi SZ, Jenabi E. The association between maternal smoking and placenta abruption: a meta-analysis. J Matern Fetal Neonatal Med. 2017;30(16):1963-1967. do i:10.1080/14767058.2016.1235694

7. Xuan Z, Zhongpeng Y, Yanjun G, et al. Maternal active smoking and risk of oral clefts: a meta-analysis. Oral Surg Oral Med Oral Pathol Oral Radiol. 2016;122(6):680-690. doi:10.1016/j.oooo.2016.08.007

8. Cui H, Gong TT, Liu CX, Wu QJ. Associations between Passive Maternal Smoking during Pregnancy and Preterm Birth: Evidence from a Meta-Analysis of Observational Studies. PLoS One. 2016;11(1):e0147848. doi:10.1371/journal.pone.0147848

9. Leonardi-Bee J, Britton J, Venn A. Secondhand smoke and adverse fetal outcomes in nonsmoking pregnant women: a meta-analysis. Pediatrics. 2011;127(4):734741. doi:10.1542/peds.2010-3041

10. Meng X, Sun Y, Duan W, Jia C. Meta-analysis of the association of maternal smoking and passive smoking during pregnancy with neural tube defects. Int J Gynaecol Obstet. 2018;140(1):18-25. doi:10.1002/ijgo.12334

11. Zhang K, Wang X. Maternal smoking and increased risk of sudden infant death syndrome: a metaanalysis. Leg Med (Tokyo). 2013;15(3):115-121. doi:10.1016/j.legalmed.2012.10.007

12. Lange S, Probst C, Rehm J, Popova S. National, regional, and global prevalence of smoking during pregnancy in the general population: a systematic review and metaanalysis. Lancet Glob Health. 2018;6(7):E769-E776. doi: 10.1016/S2214-109X(18)30223-7
13. Ministry of the Environment. National survey on children's health and environment. In Japanese. Accessed March 27, 2020. https://www.env.go.jp/chemi/ceh/ material/seminar130122_3.pdf

14. Ministry of Health, Labour and Welfare. Health Japan 21 (the second term). In Japanese. Accessed May 30, 2020. https://www.mhlw.go.jp/bunya/kenkou/dl/ kenkounippon21_01.pdf

15. Ministry of Health, Labour and Welfare. Health Promotion Act. In Japanese. Accessed May 30, 2020. https://www. mhlw.go.jp/stf/seisakunitsuite/bunya/0000189195.html

16. Michibayashi C, Omote S, Nakamura M, Okamoto R, Nakada AI. Competency model for public health nurses working on tobacco control in local governments in Japan: A qualitative study. Jpn J Nurs Sci. 2020;17(1):e12288. doi:10.1111/jjns.12288

17. The Japan Association of Public Health Nurse Educational Institutions. Where public health nurses work. Accessed June 6, 2021. http://www.zenhokyo.jp/en-public/field-en.shtml

18. Kouketsu T, Matsuda N. Postpartum smoking behavior in women and related factors. In Japanese. Nihon Koshu Eisei Zasshi. 2010;57(2):104-112.

19. Miyazaki Y, Hayashi K, Imazeki S. Smoking cessation in pregnancy: psychosocial interventions and patientfocused perspectives. Int J Womens Health. 2015;7:415427. doi:10.2147/IJWH.S54599

20. U. S. Department of Health and Human Services. Treating Tobacco Use and Dependence: 2008 Update. U. S. Department of Health and Human Services; 2008. Accessed April 29, 2021. https://www.ncbi.nlm.nih.gov/books/NBK63952/

21. Diamanti A, Papadakis S, Schoretsaniti S, et al. Smoking cessation in pregnancy: An update for maternity care practitioners. Tob Induc Dis. 2019;17(August). doi:10.18332/tid/109906

22. Joint Working Groups: The Japanese Society for Oral Health, The Japanese Society of Oral and Maxillofacial Surgeons, The Japanese Society of Public Health, The Japanese Respiratory Society, The Japan Society of Obstetrics and Gynecology, The Japanese Circulation Society, The Japan Pediatric Society, The Japanese College of Cardiology, The Japan Lung Cancer Society. Guidelines for Smoking Cessation (JCS 2010). In Japanese. Scientific Committee of the Japanese Circulation Society; 2012. Accessed March 28, 2020. https://www.j-circ.or.jp/cms/ wp-content/uploads/2020/02/JCS2010murohara.h.pdf

23. Taniguchi C, Tanaka H, Saka H, et al. Cognitive, behavioural and psychosocial factors associated with successful and maintained quit smoking status among patients who received smoking cessation intervention with nurses' counselling. J Adv Nurs. 2017;73(7):16811695. doi:10.1111/jan.13258

24. Taniguchi C, Tanaka H, Saka H, et al. Changes in selfefficacy associated with success in quitting smoking in participants in Japanese smoking cessation therapy. Int J Nurs Pract. 2018;24(4):e12647. doi:10.1111/ijn.12647 
25. Taniguchi C, Hashiba C, Saka H, Tanaka H. Characteristics, outcome and factors associated with success of quitting smoking in 77 people living with HIV/AIDS who received smoking cessation therapy in Japan. Jpn J Nurs Sci. 2020;17(1):e12264. doi:10.1111/jjns.12264

26. Taniguchi C, Hibino F, Kawaguchi E, et al. Perceptions and practices of Japanese nurses regarding tobacco intervention for cancer patients. J Epidemiol. 2011;21(5):391-397. doi:10.2188/jea.JE20110008

27. Ioakeimidis N, Vlachopoulos C, Katsi V, Tousoulis D. Smoking cessation strategies in pregnancy: Current concepts and controversies. Hellenic J Cardiol. 2019;60(1):11-15. doi:10.1016/j.hjc.2018.09.001

28. Patnode CD, Henderson JT, Thompson JH, Senger CA, Fortmann SP, Whitlock EP. Behavioral Counseling and Pharmacotherapy Interventions for Tobacco Cessation in Adults, Including Pregnant Women: A Review of Reviews for the U.S. Preventive Services Task Force. Ann Intern Med. 2015;163(8):608-621. doi:10.7326/M15-0171

29. Ministry of Health, Labor and Welfare. Smoking cessation support manual, supplementary revised edition. In Japanese. 2nd ed. Accessed March 20, 2020. https://www.mhlw.go.jp/ topics/tobacco/kin-en-sien/manual2/dl/addition01.pdf

30. National Centre for Smoking Cessation and Training. Stopping smoking in pregnancy: A briefing for maternity care providers. Public health England; 2019. Accessed March 30, 2020. https://www.ncsct.co.uk/usr/pub/ NCSCT\%20maternity\%20care $\% 20$ briefing.pdf

31. National Institute for Health and Care Excellence. Smoking: stopping in pregnancy and after childbirth. Accessed March 30, 2020. https://www.nice.org. uk/guidance/ph26/resources/smoking-stopping-inpregnancy-and-after-childbirth-pdf-1996240366789

32. e-Stat. Statistics of Japan: Survey on Public Health Nurse Activity Area. In Japanese. Accessed March 30, 2020. https://www.e-stat.go.jp/stat-search/files?page $=1 \&$ toukei $=00450471 \&$ tstat $=000001035128$

33. Yanai H, Ibe T. Measuring Nursing: The Status of Questionnaire Survey by Factor Analysis. In Japanese. Asakura Publishing; 2012.

34. Boateng GO, Neilands TB, Frongillo EA, MelgarQuiñonez HR, Young SL. Best Practices for Developing and Validating Scales for Health, Social, and Behavioral Research: A Primer. Front Public Health. 2018;6:149. doi:10.3389/fpubh.2018.00149

35. Johnston JM, Chan SS, Chan SK, Lam TH, Chi I, Leung GM. Training nurses and social workers in smoking cessation counseling: a population needs assessment in Hong Kong. Prev Med. 2005;40(4):389-406. doi:10.1016/j.ypmed.2004.07.008

36. Leung DYP, Chan SS, Jiang CQ, Lam TH. Providing Smoking Cessation Services and Its Relationship with Knowledge and Attitudes: A Comparison of the Guangzhou and Hong Kong Nurses. Journal of Comparative Asian Development. 2009;8(1):179-205. doi:10.1080/15339114.2009.9678478

37. Mak YW, Loke AY, Wong FKY. Nursing Intervention Practices for Smoking Cessation: A Large Survey in Hong Kong. Int J Environ Res Public Health. 2018;15(5):1046. doi:10.3390/ijerph15051046

38. Price JH, Jordan TR, Dake JA. Perceptions and use of smoking cessation in nurse-midwives' practice. J Midwifery Womens Health. 2006;51(3):208-15. doi: 10.1016/j.jmwh.2005.12.003

39. Sarna L, Bialous SA, Wells M, Kotlerman J, Wewers ME, Froelicher ES. Frequency of nurses' smoking cessation interventions: report from a national survey. J Clin Nurs. 2009;18(14):2066-2077. doi:10.1111/j.1365-2702.2009.02796.x

40. Sarna L, Bialous S, Ong M, Wells M, Kotlerman J. Nurses' treatment of tobacco dependence in hospitalized smokers in three states. Res Nurs Health. 2012;35(3):250-264. doi:10.1002/nur.21476

41. Sarna LP, Bialous SA, Králíková E, et al. Tobacco Cessation Practices and Attitudes Among Nurses in the Czech Republic. Cancer Nurs. 2015;38(6):E22-E29. doi:10.1097/NCC.0000000000000222

42. Sarna L, Bialous SA, Zou XN, et al. Helping smokers quit: behaviours and attitudes of Chinese Registered Nurses. J Adv Nurs. 2016;72(1):107-117. doi:10.1111/jan.12811

43. Li M, Koide K, Tanaka M, Kiya M, Okamoto R. Factors Associated with Nursing Interventions for Smoking Cessation: A Narrative Review. Nurs Rep. 2021;11(1):6474. doi:10.3390/nursrep11010007

44. De Wilde K, Tency I, Steckel S, Temmerman M, Boudrez $\mathrm{H}$, Maes L. Which role do midwives and gynecologists have in smoking cessation in pregnant women? - A study in Flanders, Belgium. Sex Reprod Healthc. 2015;6(2):6673. doi:10.1016/j.srhc.2014.12.002

\section{ACKNOWLEDGEMENTS}

The authors gratefully acknowledge other members of the Public Health Nursing Laboratory for helpful comments and advice on this manuscript.

\section{CONFLICTS OF INTEREST}

The authors have completed and submitted the ICMJE Form for Disclosure of Potential Conflicts of Interest and none was reported.

\section{FUNDING}

There was no source of funding for this research.

\section{ETHICAL APPROVAL AND INFORMED CONSENT}

The study was approved by the Ethical Committee of Observation Research at Osaka University Hospital (Approval No: 19308, November $28,2019)$. We conducted a cross-sectional study via anonymous, selfadministered questionnaire sent to public health nurses, hence receipt of the filled in questionnaire was deemed as informed consent.

\section{DATA AVAILABILITY}

The data supporting this research is available from the authors on reasonable request.

\section{PROVENANCE AND PEER REVIEW}

Not commissioned; externally peer reviewed. 